Cad.Est.Ling., Campinas, 47(1) e (2):129-141, 2005

\title{
AS MÚLTIPLAS RESSONÂNCIAS LINGÜÍSTICAS DOS DIZERES NAS PSICOSES *
}

\author{
MARILUCI NOVAES** \\ (Universidade Federal Fluminense)
}

\begin{abstract}
The construction of a hypothetical correspondence between description and analysis of data and states of psychosis is argued. Is there any legitimacy in corresponding utterances to states of psychosis? Is it possible to say that data translate the phenomena of psychosis? Is it possible to anticipate psychotic speech through any objective characteristics? How to deal with personal focus of endeavor in researching?
\end{abstract}

\section{INTRODUÇÃO}

Tudo aquilo que comparece nos dizeres nas psicoses é da ordem de uma atividade gramatical possível ou da ordem da materialidade lingüística que uma língua testemunha. Não há linguagem sem o testemunho de uma língua, por mais bizarra que seja. Naturalmente que nem tudo que é materialmente possível é lingüisticamente julgado como pertencente à língua, mas pelo menos uma de suas estruturas (fonológica, morfológica, sintática) dá as cartas da enunciação. Tal distinção, formulada por Milner (1989), marca a não-coincidência entre formas materiais possíveis que podem ser ou não descritas pelos paradigmas de uma língua. Mais relevante ainda, essas não-coincidências atestam o mal-estar dos sujeitos que se vêem imersos num meio lingüístico que não lhes garante tudo poder dizer ou escutar.

Como então falar de patologia ou normalidade quando nosso objeto de investigação, enquanto lingüistas, são as atualizações possíveis da língua em forma de linguagem? O patológico corresponderia ao material possível e não lingüisticamente julgado? O que o lingüista não pode descrever se inscreve obrigatoriamente na ordem da patologia?

Trago a questão, apresentada pelo título desta mesa-redonda - Do projeto de aquisição da linguagem às reflexões sobre o normal e o patológico - que se propõe a expor reflexões sobre o normal e o patológico, sabendo de antemão da impossibilidade de se tomar essa questão no âmbito da Lingüística. A meu ver, para o lingüista, essa é uma falsa questão.

\footnotetext{
* Este artigo apresenta um dos resultados finais da pesquisa apoiada pelo CNPq, processo no $301127 / 95$ 6, "Para uma teoria lingüística sobre os mecanismos de comunicação nas psicoses".

${ }^{* *}$ Coordenadora do Grupo de Pesquisa UFF/CNPq, Linguagens das diferenças: psicoses e outros lugares de estranhamento.
} 
A impossibilidade de descrever todas as formas materiais possíveis causa um malestar ao lingüista, sem dúvida. Se a Lingüística é a ciência da linguagem, como pode existir algo da ordem da linguagem que lhe escapa? Como, na ordem da linguagem, pode comparecer uma forma linguageira que se torne um dilema para o lingüista entre apresentar uma descrição possível julgada gramaticalmente pertinente, colocando-se como sujeito de uma fala que não é sua, ou refutá-la como "erro", como "desvio lingüístico" ou como "comportamento verbal patológico"?

O impasse do lingüista, portanto, é colocar-se como sujeito de uma fala que não é a sua, já que só há descrição possível se ele tomar como parâmetro de descrição a sua competência lingüística. O que o lingüista descreve é o que ele, enquanto falante da língua, pode falar. Chamar de linguagem patológica, portanto, aquilo que foge à competência lingüística do lingüista (vejam bem que não estou considerando uma competência lingüística do falante nativo ideal, nos modelos propostos por Chomsky), aquilo que se apresenta a ele como estranho (cf. a noção de estranhamento desenvolvida em Novaes, 1996) ou como enigma, pode ser um jeito de evitar o mal-estar diante de um real indistinto, disperso, que contorna as formas materiais porém não-descritíveis. O sentido do termo real, usado aqui, deriva das formulações propostas por Milner (1983), a partir da psicanálise proposta na obra de Lacan, como algo irrepresentável, portanto inexoravelmente fora da linguagem. Não se confunde, contudo, com a acepção da palavra mais comum de realidade, de mundo objetivo independente da relação dos sujeitos com ele. Assim, o real aqui não é o mesmo para todos os sujeitos, pois depende de suas relações com os outros registros do imaginário e do simbólico. As formas materiais e não-lingüísticas enganam a compreensão do lingüista, sendo pura materialidade que tenta dar um sentimento de realidade à linguagem, "num manejo imprudente da relação com o objeto" (Lacan, 1988 [1955-56], p. 24).

\section{CORPO \& CORPUS}

Para quem leu o artigo "Corpo \& Corpus", de autoria de nossa homenageada neste Seminário Comemorativo de 25 anos do Projeto de Aquisição de Linguagem, Cláudia Thereza Guimarães de Lemos, pode já ter percebido que faço referência indireta a ele, pela inquietação que ele causa a quem se dispõe a trabalhar com dados. Meu banco de "dados" de pesquisa é composto de gravações e de transcrições ou de textos escritos por sujeitos submetidos a estados de psicoses, obtidos desde 1991, ano em que generosamente Cláudia me escutou e apostou no meu trabalho de doutoramento sobre o tema. Fazer um diálogo com seu texto, expondo os movimentos de estranhamento e de enigma dos dizeres de psicóticos, é a forma carinhosa que escolhi para homenageá-la.

No artigo "Corpo \& Corpus", De Lemos constata a persistência do uso da forma latina corpus, com seu plural corpora, no campo da aquisição da linguagem e indaga: a partir da definição de corpus, como um conjunto de gravações e de transcrições que servem de referência para a descrição de um objeto, é possível descrever a "fala da criança"? No campo da aquisição da linguagem, o que se descreve, a fala ou o que "sobra da fala escoada pelos ouvidos da máquina e do investigador?" 
Cadernos de Estudos Lingüísticos 47(1) e (2) - Jan./Dez. 2005

O ponto principal da argumentação formulada por De Lemos, parece-me, é a legitimidade da correspondência entre dados transcritos e o sujeito-criança que se apresenta na fala e, mais ainda, se é legítimo afirmar que os dados transcritos representam a entidade criança. Nesse último caso, a tradicional metodologia de se apresentarem estudos longitudinais num certo período da vida da criança confirma que as mudanças na fala são tomadas como estágios de desenvolvimento da relação da criança com a língua nas diferentes faixas etárias. Apesar da constatação de que não há uma fala, mas várias falas, mantém-se ainda assim intacta a entidade criança.

A busca da legitimidade da descrição de um objeto pode se dar nas crenças da "sofisticação dos equipamentos de registro em áudio e vídeo" e/ou da inclusão da descrição de gestos (normalmente o foco é mais a criança do que a mãe ou o investigador) e de todo material presente na cena enunciativa, que o investigador seleciona como representativo e significativo na descrição. Atribui-se assim aos instrumentos de registro as possíveis imprecisões nas descrições.Tais tentativas não seriam fruto de uma certeza de que o lingüístico por si só não garante a legitimidade da correspondência? A busca dos para- e extra-lingüísticos não confirmaria ainda a crença de que o corpus efetivamente representa a criança?

Assim, os corpora no campo da aquisição de linguagem representariam a entidade criança, apreendida como um todo. E mesmo se tomarmos o termo corpus "consagrado no estruturalismo americano enquanto conjunto finito de enunciados de línguas a serem decifradas/ descritas [...] para nomear o registro longitudinal da fala que documentaria a trajetória da criança pela língua", como garantir a fidedignidade de uma descrição estática realizada por um investigador num estágio de saber da língua que não corresponde àquele da criança? Se tomamos essas descrições como "formas possíveis de aproximação do lingüista" (expressão usada por Hockett, e citada em De Lemos) a um estágio de língua que não é o seu, que substância é essa e que funcionamento estranho é esse aos quais o investigador fica submetido ao crer que pode, a partir de seu estágio de competência lingüística, "acessar" um estágio em desenvolvimento? Que outras "formas possíveis" ficam de fora da aproximação do lingüista?

Um outro ponto colocado em questão quando se trata do uso de corpora na descrição lingüística refere-se à sua representatividade como amostra descritiva de uma língua. A representatividade é que garante a predição das "relações entre os elementos de qualquer outro corpus da língua" (Harris, 1951, p. 12 e ss, citado em De Lemos). No caso da criança, como afirma De Lemos, "pretendia-se partir de sua fala para chegar a conhecer o que ela, a criança, conhecia da língua ou como viria a atingir esse conhecimento enquanto totalidade necessária". A diferença individual, contudo, torna-se um obstáculo à predição, fazendo com que "do corpus de antes só restassem episódios, nos quais irrompe uma criança através de uma fala inesperada".

Em resumo, a partir da leitura muito particular que realizei do texto de De Lemos, tendo em vista as inquietações que tenho quando trabalho com gravações de entrevistas e textos escritos realizados em instituições psiquiátricas, destaquei duas questões: a legitimidade da correspondência entre os dizeres e os estados de psicoses e a representatividade e conseqüente predição de todas as relações entre os elementos de quaisquer outros dizeres que identificariam o dizer psicótico. 


\section{A LEGITIMIDADE DA CORRESPONDÊNCIA ENTRE OS DIZERES E OS ESTADOS DE PSICOSES}

Conforme constata De Lemos, "o investigador só poderá ouvir/escutar os sons da fala quando deixar de ouvi-los enquanto sons para apreendê-los enquanto figuras a serem transcritas". "Das múltiplas ressonâncias lingüísticas dos dizeres nas psicoses", título deste artigo, propõe-se assim a refletir sobre algumas "formas possíveis" de aproximação do lingüista aos dizeres de indivíduos submetidos a estados de psicoses, vistas menos como formas e mais como escrituras possíveis derivadas de ressonâncias lingüísticas na passagem de uma substância inicial, a substância fonética, para um texto de análise daquilo que a investigadora nomeou "dizeres nas psicoses" (Novaes, 1996).

Identificar o que seja um estado de psicose ${ }^{1}$ não é tarefa do lingüista. Quem caracteriza o diagnóstico da doença é o psiquiatra. Assim, todas as gravações em áudio ou em vídeo que são produzidas em instituições psiquiátricas com seus usuários poderiam, por princípio, fazer parte de análises de dizeres em estados de psicoses. Normalmente, também, é o psiquiatra quem indica os usuários para o lingüista, a partir de diagnósticos de esquizofrenias, síndromes maníaco-depressivas, etc. O lingüista, portanto, não tem que confirmar ou negar que seu material de análise foi produzido por psicóticos. Assim, de antemão, o lingüista esperaria que seus dados confirmassem o que ele já sabia: as falas analisadas correspondem a estados de psicoses.

O primeiro problema decorrente disso, que considero uma fatalidade incômoda, poderia ser a busca da correspondência dos desvios lingüísticos com os estados de psicoses. Esse seria o objetivo do lingüista que tomasse as categorias de normal e de patológico como representativas de um certo conjunto de indivíduos. Não é a minha proposta de investigação. A inclusão dessas categorias já marcaria as "formas possíveis de aproximação", pois um modelo de desempenho normal e ideal serviria de parâmetro para a confirmação do patológico e, junto com ela, a expectativa da correção, na transformação do indivíduo naquilo que se supõe ele era antes de ser acometido pela doença. Assim, de uma certa maneira, o trabalho com os corpora constituídos de gravações com psicóticos é semelhante a esse movimento de supor que se parte de um estágio representante de um não-todo, da falha, para o estágio da estabilização da língua, com um fator de complicação de que se supõe que haveria um estágio anterior de normalidade. Outro fator seria julgar enunciados a partir de competências linguísticas semelhantes (o psicótico, até onde pude observar em minhas pesquisas, não demonstra desconhecer regras e estruturas gramaticais), mas de diferentes tipos de relação com a língua. A questão psicótica é uma questão semânticopragmática no que diz respeito à atribuição de sentidos aos enunciados.

\footnotetext{
${ }^{1}$ O uso de termos como "psicose" e "psicóticos" não é consenso nem na Psiquiatria nem na Psicanálise. Em alguns trabalhos, sigo uma distinção entre esquizofrenia e paranóia apresentada ao longo das obras de Lacan e Freud. De uma certa maneira, tento evitar me comprometer com discussões terminológicas acerca desses termos e de outros como "indivíduos com transtornos mentais", "doentes mentais" e as classificações mais específicas das diversas manifestações de distúrbios mentais.
} 
Cadernos de Estudos Lingüísticos 47(1) e (2) - Jan./Dez. 2005

A inclusão fatal das categorias de normal e de patológico não decorreria, portanto, da crença de que todos os sujeitos falantes de uma língua mantêm a mesma relação com ela, em todas as situações enunciativas? Qual seria então o interesse teórico para a Lingüística de se incluírem em seu campo de atuação essas categorias?

$\mathrm{O}$ que interessa à Lingüística, parece-me, é evidenciar que os dizeres nas psicoses mostram ao lingüista algumas possibilidades limites da materialidade da língua, a partir das quais não há mais possibilidade de escuta. Ouvir a gente pode ouvir, mas só se escuta aquilo que promete alguma forma de significação. Os dizeres nas psicoses, resultantes de uma escuta possível, testemunham os limites da materialidade, para além do previsível e do gramatical.

Assim, a transformação da substância fônica em dizer torna-se um desafio por duas razões: primeiro, porque se tem que trabalhar num limite entre um material possível e o que fica por escutar e, segundo, porque se tem também que trabalhar no limite entre o gramatical e o agramatical. O desafio se mantém na determinação desses limites que não se encontram propriamente nas falas gravadas (não se trata de limitações dos instrumentos de registro das falas nem das condições de gravação), mas sim nas escrituras possíveis para os dizeres nas psicoses propostas pelo lingüista.

Reparem no dizer, a seguir, proposto a partir de uma gravação em áudio que fiz com Gladison, usuário de uma instituição psiquiátrica no Rio de Janeiro ${ }^{2}$ :

G: Sabe? ... então, doutora ... seu nome é?

M: Mariluci

G: Mariluci

M: Mariluci

G: Então ... é, é o seguinte o que tá perturbando hoje em dia se parece o seguinte trago o seio da metamorf ... da bagunça.

M: Mas você acha ... quem faz a bagunça?

G: Fez a bagunça? Fez a bagunça foi aquela (...) que nós falamos a respeito daquele trato e nós saindo .... (ininteligível) ... não tá mais, compreendeu? Então se nós ficarmos perto, sabe? Um do outro fisicamente

(M. interrompe G.)

M: Você quer dizer um ajuda o outro ...

(G. interrompe M.)

G: Nós vivemos nosso pacto fisicamente. Nós queremos explicar o seguinte: ... (ininteligível) ... e deixar pra lá até tudo que fosse preciso ... compreendeu?

A extrema estranheza ao ouvir "o que tá perturbando hoje em dia se parece o seguinte trago o seio da metamorf ... da bagunça" resultou de minha não-competência em reconstituir

\footnotetext{
${ }^{2} \mathrm{Na}$ ilusão de que havia mais a se escutar nas fitas gravadas com as entrevistas do Gladison, submeti-as ao Laboratório de Fonética do IEL (na época do meu período de doutoramento). As incompletudes, naturalmente, não foram resolvidas, o único "dado" obtido a mais foi que havia uma esgarçadura na articulação dos sons das palavras, produzido possivelmente pelos efeitos da medicação que Gladison tomava, nada que "alterasse" os dizeres que propus para a pesquisa.
} 
a construção sintática de Gladison, composta de seqüências sintagmáticas gramaticais e seqüências agramaticais encaixadas ou interrompidas. Da estranheza incômoda, resultou minha tentativa de trazer o Gladison para uma escuta mais cômoda, na qual o gramatical poderia ser restabelecido nas lacunas que considerei ininteligíveis: "mas você acha ... quem fez a bagunça?" Tentar arrumar uma relação entre sintagmas, obviamente, não surtiu efeito. O estranhamento era meu e não de Gladison. Se eu não podia escutá-lo, tampouco podia ele se escutar e compartilhar o meu estranhamento.

Ouso afirmar que se pode falar em uma correspondência somente entre esse dizer de Gladison e o estado de psicose que irrompe nele, o que não garantiria que essa mesma correspondência se mantivesse na mesma relação com outros dizeres seus. Se esse tipo de construção sintática pode corresponder a um determinado estado de psicose, não há predição alguma de que essa construção sintática seja mantida em outros dizeres do Gladison e em todos os dizeres de outros psicóticos.

Observem um outro dizer de Gladison, proposto a partir de uma outra gravação, uma semana depois:

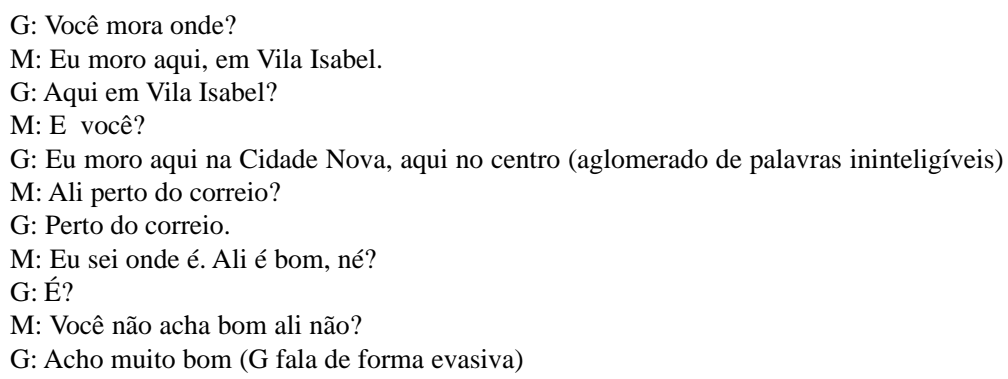

Independentemente do paralelismo do qual eu e meu entrevistado não escapamos "moro aqui ...aqui em ... moro aqui... aqui no centro... ali perto ... ali é bom... não acha bom ali não..." - o dizer acima mostra de forma radical que no meio de sequiências previsíveis, apoiadas provavelmente pelo paralelismo realizado a partir de minhas perguntas e respostas, numa tentativa de colocar meu entrevistado no cabresto de minha escuta, inesperadamente surge o que chamei de "aglomerado de palavras". A sensação acústica era exatamente essa, uma impossibilidade de fazer qualquer tipo de corte na seqüência fônica.

Esse paralelismo que eclodiu com formas materiais possíveis correspondentes a formas lingüisticamente descritíveis alerta, todavia, que o lingüista também é submetido a uma deriva que o coloca num jogo paradigmático-sintagmático ilusório de controle. É certo que o corte na entrevista foi determinado por mim, a partir de um elemento teórico com o qual queria trabalhar, mas a tal "objetividade" do lingüista é uma mera quimera - a fala do psicótico produziu efeitos na fala do lingüista. Como então falar em legitimidade de correspondência entre um dizer e um estado de psicose, se o limite da distinção entre inteligível e ininteligível é dependente de minha escuta e se minha fala é submetida aos 
Cadernos de Estudos Lingüísticos 47(1) e (2) - Jan./Dez. 2005

efeitos da fala de meu entrevistado, dando-lhe uma "direção" que só diz respeito àquela cena enunciativa?

\section{A REPRESENTATIVIDADE E A CONSEQÜENTE PREDIÇÃO DE UM DIZER PSICÓTICO}

Há um interesse crescente em filmes e livros com personagens em estados alterados da mente, psicóticos ou não, mas que são compostos com características correspondentes aos sintomas de transtornos mentais descritos nos manuais de Psiquiatria. Seriam essas outras "formas possíveis" de aproximação do lingüista aos dizeres psicóticos? A análise desses personagens psicóticos comprovaria a representatividade de sintomas de linguagem presentes nas psicoses? A partir da descrição dessas representações poderíamos predizer outros dizeres, na literatura ou não?

São várias as representações, mas normalmente é o delírio o sintoma escolhido para representar a alteração da mente (para citar alguns, Bicho de Sete Cabeças, K-Pax, Uma mente brilhante, Shine, Crônica de uma certa Nova York, O pescador de Ilusões, Mistérios e Paixões, O dragão vermelho, Stigmata, Pi, Madre Joana dos Anjos, Os Outros, De olhos bem fechados, O iluminado, Spider: desafie sua mente). As interpretações que são dadas a esses delírios variam muito, mas o curioso é que, sendo os delírios produções de linguagem, é exatamente na construção das falas dos personagens que a verossimilhança se perde.

Apesar de haver diferenças consideráveis na composição dos personagens e das razões propostas para os distúrbios da mente apresentados, a verossimilhança dessas obras costuma falhar exatamente na construção dos delírios. Os efeitos de linguagem resvalam para além dos efeitos de transtornos mentais que afinal deveria ter um delírio para ser caracterizado como sintoma de psicose. Em contrapartida, normalmente toda a composição extra- e paralingüística, em gestos, hábitos, relações com o mundo etc., guardados os exageros da apologia da loucura como religiosidade, paranormalidade, liberdade e criatividade, oferece elementos verossimilhantes e previsíveis de caracterização de alguns estados de psicoses. Em resumo, o delírio, enquanto linguagem, é o sintoma-chave de um surto psicótico, mas "produzi-lo literariamente ou em um roteiro cinematográfico" é uma tarefa impossível.

Por que haveria esse descompasso quanto à fidedignidade do lingüístico e do paralingüístico na representação das psicoses? Por que a predição falha quando se trata de linguagem verbal, de delírio? Em Spider: desafie sua mente, por exemplo, baseado no livro Spider, do escritor inglês Patrick McGrath, o roteiro também foi elaborado por $\mathrm{McGrath}^{3}$. Surpreendentemente, o Sr. McGrath modifica cenas (no livro não há a cena do assassinato da mãe), altera nomes de personagens centrais na narrativa (o nome do pai de

${ }^{3}$ A análise dos efeitos de estados de psicoses entre o filme e o livro Spider é uma versão ampliada da apresentação oral durante o Seminário Comemorativo. Na época, o filme ainda não havia entrado em cartaz no circuito normal dos cinemas do Rio de Janeiro. 
Horace para Bill, o da amante do pai de Hilda para Yvonne), refaz acontecimentos delirantes que Spider anota em seu diário, acrescenta cenas (o Spider tentando montar um quebracabeças na pensão que o acolhe após uma internação prolongada), elimina cenas (como as que revelam a longa internação no Canadá), altera a ordem dos fatos que estavam no livro. Perfeitamente natural a liberdade do roteirista de apresentar uma versão modificada do delírio de Spider, mesmo tendo sido ele o autor do livro com a narrativa-base da história. Poderíamos pensar que na tentativa de adequar o roteiro à linguagem cinematográfica, McGrath tenha feito tais alterações.

Nada disso seria motivo para comentário em artigo, se, ao fazer essas alterações, o Sr. McGrath não produzisse no roteiro do filme efeitos lingüísticos e paralingüísticos que poderíamos dizer que predizem efeitos de estados de esquizofrenia, enquanto, no livro, a narrativa em $1^{\text {a }}$ pessoa do personagem Dennis (ou Spider), que ficamos sabendo ao longo da narrativa que é esquizofrênico, produz outros efeitos e o delírio apresentado não caracteriza a esquizofrenia. Simplesmente, no roteiro, as falas de Spider são mínimas, interrompidas, desconexas e quem "constrói” o delírio através das imagens e da interpretação estupenda de Ralph Fiennes é o espectador. A excelente direção de David Cronenberg também coopera com o estranhamento causado pelo cenário, sempre com espaços desertos e sempre centrados a partir do ponto de vista de Spider. Os outros personagens, todos também estranhos, mantêm o ar de algo surreal. No filme, a mesma atriz (Miranda Richardson) faz o papel da mãe e da amante do pai de Spider. Com isso, a narrativa delirante de Spider, que se concentra na crença de que o pai matou a mãe para poder ficar com a amante e colocá-la na sua casa, ganha força retórica.

Ralph Fiennes, no papel de Dennis e de Spider, representa de forma extremamente verossímil um psicótico atormentado por seus delírios, um usuário das diversas instituições psiquiátricas que visitei como pesquisadora nos últimos doze anos. Sem tirar, nem pôr, seu Spider me causou efeitos de estranhamento semelhantes aos que alguns usuários dessas instituições me causam. No filme, McGrath, como roteirista, juntamente com a engenhosidade de Cronenberg, o diretor, conseguiram o êxito de compor um personagem verossimilhante tanto em suas poucas falas quanto em suas encenações não-enunciativas.

No livro, o leitor é convidado a entrar na mente esquizofrênica de Spider. No filme, segundo o diretor de cinema David Cronenberg, o filme é sobre a esquizofrenia, mas "eu me acho incrivelmente são". A preocupação de Cronenberg em não querer ser sujeito da narrativa é compreensível, o personagem de Ralph Fiennes, tanto em suas falas interrompidas (diferentemente do livro em que os delírios são elaborados verbalmente e acabam causando efeitos outros alheios às psicoses), quanto em suas movimentações estranhas, chega muito próximo da representação de um esquizofrênico em estado de psicose.

No filme, Spider constantemente fala com suas vozes, há um murmúrio constante ininteligível pontuando seus movimentos na composição do delírio que ele tenta escrever num diário que nós, espectadores do filme, não conseguimos ler, já que os apontamentos são registrados de forma também ininteligível e anárquica, tomando todo o espaço da folha em todas a s direções. Brilhantemente, $\mathrm{McGrath}$ manteve em seu roteiro essa relação com a escrita que os psicóticos costumam ter. Manteve ainda o balbucio constante na 
Cadernos de Estudos Lingüísticos 47(1) e (2) - Jan./Dez. 2005

interação com as vozes, convidando-nos enquanto espectadores a "preencher essas falas interrompidas" para darmos sentidos aos tormentos de Spider. A presença magistral de Spider sempre como observador das cenas que compõem o delírio em que "ele" aparece como menino marca esse caráter de distanciamento entre o sujeito que delira e seu delírio, exatamente como os psicóticos marcam ao atribuir os fatos do delírio como de responsabilidade das vozes que ouvem e que lhes dão ordens. Afinal, Spider mata a mãe, mas atribui o crime ao pai.

No livro, McGrath usou e abusou de situações e temas que costumam estar presentes nas síndromes psicóticas, segundo os manuais de Psiquiatria e de Psicanálise: relatos de corpos despedaçados, identidades contraditórias, vozes alucinatórias que dão ordens ameaçadoras, alucinações olfativas, estereotipias, manias, quadro persecutório etc. Montou, apesar de todo esforço narrativo, uma história de terror.

Em um outro livro seu, intitulado Manicômio, ficamos sabendo, por informação da editora Companhia das Letras, que o Sr. McGrath foi criado perto do Hospital Psiquiátrico de Broadmoor, na Inglaterra, do qual seu pai foi diretor médico por um longo tempo. Tal fato pode talvez explicar o sucesso de seu roteiro, mas também, em decorrência disso talvez, as situações narradas que tentam garantir no livro a verossimilhança de uma narração de uma mente atormentada pela esquizofrenia pecaram exatamente por ele ter levado a sério a certeza da representatividade dos efeitos de linguagem de estranhamento nas psicoses. Vejam o seguinte trecho:

\footnotetext{
Uma monstruosidade anatômica, sem dúvida: o intestino delgado foi enrolado em volta da parte inferior da espinha dorsal, bem apertado, e ascende por ela em espiral muito justa, engrossando na altura do cólon, na metade do caminho, que por sua vez envolve a parte superior da coluna como uma jibóia, o reto passa através do meu cérebro e o ânus se posicionou no alto da cabeça, onde se criou uma abertura entre os ossos que formam o topo, que eu apalpo constantemente, horrorizado, uma espécie de moleira com orifício excretor (meu cabelo só não está sujo e fedorento por causa da chuva bendita que diariamente me limpa) ... a matéria apodrece lentamente dentro de mim, restos de órgãos desnecessários, e por causa dos odores liberados por esse processo que começaram a sair pelos poros de minha pele (minha pele! Meu casco, minha concha, minha casca!) revesti meu tronco e todos os membros com jornal e papelão ondulado, mantidos na posição com fita adesiva, barbantes, elásticos, o que pude pegar na casa. (p. 190)
}

A tessitura montada de um corpo todo despedaçado é fantástica, contudo não causa o estranhamento de um dizer psicótico. Porque nas psicoses não há um corpo a se descrever, muito menos suas partes. No livro há um excesso de detalhes nas construções sintagmáticas que se entrelaçam para formar uma imagem de um monstro. Ao formar tal imagem, observase que muito mais do que tentar contornar um real ameaçador se está sim controlando uma relação com o objeto visado de referência. É preciso um objeto que dê veracidade ao nonsense, há uma preocupação excessiva em se construir esse objeto, enquanto na psicose não há objeto a ser construído, o real fica em estado latente impedindo que um objeto surja, descritível, que bloqueie a ameaça do irrepresentável, daquilo que está e sempre ficará fora da linguagem. Portanto, na literatura e nos filmes que tentam construir delírios para a verossimilhança de suas histórias, eles levam a sério demais a necessidade de dar um sentimento de realidade à linguagem. 
A tensão entre o gramatical e o materialmente possível produz efeito de horror na narrativa de Spider, o que mostra que nem essa tensão, normalmente presente no material que possuo no banco de dados de minha pesquisa, pode ser considerada representativa das psicoses. A tensão aqui é fruto de se construir um objeto de qualquer forma que dê suporte à linguagem. Nas psicoses, a tensão vem exatamente dessa impossibilidade, porque a certeza do delírio psicótico prescinde de objetos que garantam a sua verdade. A tensão está no limite da representabilidade dessa certeza e além dele, há um real destruidor. Por isso que para o psicótico é uma questão de vida ou morte do sujeito. Enquanto representa, há fala, enquanto há fala, há sujeito.

No filme, talvez a cena mais próxima da descrição acima é aquela em que Spider, desesperado, tira as diversas camisas que se sobrepõem uma a outra e começa intempestivamente a se enrolar em folhas de jornal e papelões amarrados com barbantes na altura do abdômen. O inusitado da cena parece testemunhar melhor a idéia do despedaçamento do corpo.

Reparem o dizer de Egberto (usuário de uma instituição psiquiátrica), proposto a partir de uma entrevista com um psiquiatra em que ele relata também um certo mal-estar com o corpo:

M.: É ... em que parte do corpo que começou você ... a perder a força?

E.: Começou sempre na parte daqui de dentro do testículo pênis ... essa parte da genitália

M.: Ah é?

E.: É

M.: Você começou a perder força aí?

E.: É ... a força ia toda pra aí ... quando fazia um pouquinho ... de peso ... sentia ali como se fosse realmente ... um tipo uma hérnia

M.: Sei ... e isso se traduzia como?... quando você se levantava ?... como é que acontecia isso?

E.: É ... quando eu me levantava entende? ... eu não consegui mais controlar o peso do meu corpo

M.: Sei ... mas você chegava a cair?

E.: Não ... cair não ... por exemplo ... as pernas ... eu tinha força nas pernas ... como eu tenho ... e força nos braços ... eu só não conseguia me abaixar ... pra pegar alguma coisa assim abaixado ... por exemplo eu podia pegar um até ... um bujão de gás mas tudo com através da força do tórax pra cima né ... mas abaixar assim eu não conseguia pegar nem ... uma um bal baldinho d'água ... ardia tudo aqui ... e a dor vinha tudo pra aqui assim entre o umbigo .... e a parte do testículo.

M.: E você consegue se relacionar sexualmente ... normalmente?

E.: Eu ... pra ser normalmente ... eu tenho que usar uma ... uma cinta ... apertando aqui assim

M: Sei

E: Tipo como fosse uma ... bolsa escrotal

M.: E essa cinta ... qual é a função dela?

E.: Essa cinta ... ela apóia né ... apóia a parte do (testículo pra cima) ... como se fosse uma ... uma articulação aqui assim ... uma articulação entre a parte genitália que é que não deixa ... não sei explicar M.: Então você precisa que a genitália fique ah ... suspendida ... é isso?

E.: É

M.: A bolsa escrotal ... é isso?

E.: É isso é a parte que ajuda também né ... porque se eu apertar a parte também aqui da cintura assim ... e alguma coisa da parte da espinha ... ele ... consegue também 
Não se sabe do que Egberto está falando. Nem tampouco ele está descrevendo qualquer acontecimento com seu corpo. As inúmeras frases interrompidas no dizer de Egberto marcam que há algo por ser dito que fica aquém da substância fônica. Apesar de as sequiências materializadas poderem ser consideradas gramaticais, continua havendo uma indeterminação nos efeitos de sentidos que rarefazem essa gramaticalidade, colocando-a apenas como uma forma de materialidade. Ou seja, em termos lingüísticos, as lacunas entre sintagmas não acontecem da mesma forma. No caso do dizer de Gladison [1], a interrupção se dá entre sintagmas completos, sem marca de pausa na fala. No caso de Egberto, além das pausas, as interrupções ocorrem dentro dos próprios sintagmas. Sendo frases interrompidas, um fenômeno observado normalmente nos dizeres nas psicoses, poderia parecer que qualquer interrupção seria da ordem da esquizofrenia. Não é o caso, mas no filme esse foi o recurso-chave para compor a narrativa delirante de Spider. Numa das primeiras cenas do filme, Spider volta ao terreno onde seu pai plantava batatas e onde ele achava que seu pai teria enterrado sua mãe ,após matá-la. Ele se deita em cima de um dos canteiros, encosta o rosto na terra e diz:

[5] mamãe .... só quero ficar com você ... você é um amor, sabia? .... mamãe por favor .... veja.... veja como ... sabe ... minha mãe ... ela era .... ela era ela era tão ...

Não há essa cena no livro. A volta ao canteiro de batatas é relatada assim:

[6]

Pelo caminho segui, arrastando os pés na lama, a trilha estava cheia de barro e poças, não me importei com isso e cheguei até o portão do terreno de meu pai. Nada havia mudado. Abri o portão e avancei pelo caminho, vendo os pés de batata dos dois lados ... nenhuma das ondas de terror absoluto vertiginoso que meu pai provocava no local e que acabou com o passar do tempo a assombrá-lo, até que o levou ao limite da sanidade - nada disso, nem quando me voltei novamente para o solo, senti o horror ali, pois a chuva traz paz aos vivos e aos mortos, a todas as coisas sob o chão e debaixo d'água, todas descansam em paz na chuva. Ajoelhei-me no canteiro de batatas e encostei a cabeça no chão; então, uma voz soou: "Ei, o que está fazendo aqui?" Aqui, aqui, aqui aqui aqui aqui aqui aqui. Ecoava quando me virei, tropeçando, na direção do som emitido por uma figura barbada de boné e capa de chuva do outro lado da cerca (p. 53)

McGrath precisa, no livro, construir um referente para esse estranhamento de algo falar de dentro da terra e um cenário assombroso que apóie a atitude insólita de Spider de deitar com o rosto na terra no lugar onde ele crê que sua mãe foi enterrada.

\section{CONCLUSÃO}

Como então falar de patologia ou normalidade a partir das descrições e análises de dizeres nas psicoses? O patológico corresponderia ao materialmente possível e não lingüisticamente julgado? $\mathrm{O}$ que o lingüista não pode descrever se inscreve obrigatoriamente na ordem da patologia? É possível descrever a "fala do psicótico"? Os delírios seriam formas linguageiras de construções de narrativas nonsense? Tudo que é nonsense pode ser considerado dizer psicótico? 
Obviamente que não. Se o lingüista pudesse marcar, a partir de suas descrições, esse limite entre normal e patológico, isso levaria à possibilidade de se predizerem os dizeres nas psicoses, os quais poderiam naturalmente ser reproduzidos nos livros e nos filmes. E o nonsense tem a ver com aquilo que dá sentimento de realidade à linguagem. O psicótico não precisa disso, ele pode até dar e assim o faz elementos de suporte para sua narrativa, elementos argumentativos a respeito de sua certeza, mas isso continua sendo da ordem do lingüístico e/ou do linguageiro, e não dos possíveis objetos que se queiram colocar como referentes.

A tensão entre o gramatical e o agramatical, portanto, entre o descritível e o indescritível, coloca em questão apenas os limites da materialidade possível de uma língua, que não necessariamente têm que ser atrelados às categorias de normal e de patológico. Importante notar que, quando se ultrapassa o limite da gramaticalidade, aquilo que poderíamos chamar de formações linguageiras confronta o lingüista em sua própria relação com a língua e com o real, já que quem garante uma dimensão de inteligibilidade é ele.

Podemos dizer que McGrath se viu diante desse dilema no livro: até onde se pode ir sem ultrapassar a dimensão da inteligibilidade na escritura em $1^{a}$ pessoa de um sujeito esquizofrênico? Se, para compor a "fala" de Spider, ele teve que ultrapassar seu próprio limite de formações linguageiras agramaticais, porém possíveis materialmente, o estar diante do real (aquilo que contorna a dimensão da inteligibilidade) levou-o a produzir sequiências verbais bizarras com efeitos de sentidos até então estranhos a ele. Tão bizarras que ele também teve que construir objetos bizarros como referentes.

Contudo, a narrativa de Spider não produz efeitos de sentidos de uma "mente atormentada" pela esquizofrenia, como é a proposta do autor, mas efeitos de sentidos que apontam para um sujeito atormentado por alucinações olfativas, auditivas, visuais da ordem do horror. Todas essas alucinações devidamente descritas com riquezas de detalhes. Diferentemente dos dizeres de Gladison e de Egberto, em que o que pauta a produção linguageira é o sofrimento de representar uma certeza sobre algo que só existe em sua própria experiência de sujeito na linguagem.

Porém, isso não me autoriza a dizer que essa tensão seja representativa de um dizer psicótico. Falar em "o dizer psicótico", portanto, é estar no campo da ficção, no qual a representatividade é necessária à verossimilhança, mas uma representatividade de elementos caricaturais transpostos da Psiquiatria e da Psicanálise.

Falar de dizeres nas psicoses é falar de escritas possíveis, a partir de escutas possíveis na transliteração da substância fônica, já que não há possibilidade de se ter acesso ao fenômeno psicótico. Portanto, quando no título eu marquei uma relação entre múltiplas ressonâncias lingüísticas e dizeres nas psicoses, eu estava querendo afirmar que toda análise de dizeres nas psicoses decorre de uma escritura possível, dentre outras, derivada dos efeitos de ressonância fonética sobre o investigador, que transforma os sons em formas lingüísticas e/ou materialmente possíveis, gramaticais ou agramaticais. Os limites dessas escrituras não estão no caráter normal ou patológico da fala em si, mas nos limites do investigador de apresentar uma ficção verossímil para seus pares.

No campo da literatura, McGrath foi bem-sucedido em sua narrativa de horror (ele vem sendo chamado de novo Edgard Allan Poe da literatura inglesa) e no campo de roteiro para cinema, também, o filme Spider é excelente. As diferenças significativas que McGrath 
Cadernos de Estudos Lingüísticos 47(1) e (2) - Jan./Dez. 2005

apresenta nas duas versões da história de Spider para o livro e para o cinema ressaltam evidentemente que são vários os efeitos de sentidos que uma narrativa sobre o mesmo tema pode produzir. No caso das psicoses, infelizmente não há possibilidade desse manejo lingüístico que permita aos sujeitos darem uma nova versão para seus sofrimentos e certezas.

\section{REFERÊNCIAS BIBLIOGRÁFICAS}

CANGUILHEM, G. (2002). O normal e o patológico. Trad. de M. T. Redig de Carvalho Barrocas e L. O. F. Barreto Leite. $5^{\mathrm{a}}$ ed. Rio de Janeiro: Forense Universitária.

MILNER, J-C. (1989). Les noms indistincts. Paris: Éditions du Seuil. (1989). Introduction à une science du langage. Paris: Éditions du Seuil.

LACAN, J. (1988). Seminário 3: As psicoses (1955-1956). 2a ed. Rio de Janeiro: Jorge Zahar Editor.

De LEMOS, C. T. G. Corpo \& Corpus. Trabalho apresentado na I Jornada sobre Corpo e Linguagem, IEL/ Unicamp, Campinas, Novembro de 2001 (versão mimeo).

McGRATH, P. (2002). Spider. Trad. de Celso Nogueira. São Paulo: Companhia das Letras. (2001). Manicômio. Trad. de Henrique W. Leão. São Paulo: Companhia das Letras.

NOVAES, M. (1996). Os dizeres nas esquizofrenias: uma cartola sem fundo. São Paulo: Escuta. 